\title{
Affect and Cognitive Interference: An Examination of Their Effect on Self-Regulated Learning
}

\author{
Georgia Papantoniou, ${ }^{1}$ Despina Moraitou, ${ }^{2}$ Maria Kaldrimidou, ${ }^{1}$ \\ Katerina Plakitsi, ${ }^{1}$ Dimitra Filippidou, ${ }^{1}$ and Effie Katsadima ${ }^{1}$ \\ ${ }^{1}$ Department of Early Childhood Education, School of Education, University of Ioannina, 45110 Ioannina, Greece \\ ${ }^{2}$ School of Psychology, Aristotle University of Thessaloniki, 54124 Thessaloniki, Greece \\ Correspondence should be addressed to Georgia Papantoniou, gpapanto@uoi.gr
}

Received 3 August 2012; Revised 6 November 2012; Accepted 11 November 2012

Academic Editor: Bracha Kramarski

Copyright (c) 2012 Georgia Papantoniou et al. This is an open access article distributed under the Creative Commons Attribution License, which permits unrestricted use, distribution, and reproduction in any medium, provided the original work is properly cited.

\begin{abstract}
The present study examined the relationships among affect, self-regulated learning (SRL) strategy use, and course attainment in the didactics of mathematics (teaching mathematics) subject matter domain. The sample consisted of 180 undergraduate students attending a didactics of mathematics course (mean age $=21.1$ years) at the School of Early Childhood Education. The participants were asked to respond to the Positive and Negative Affect Schedule (PANAS) and the Cognitive Interference Questionnaire (CIQ). They also completed the Learning Strategies Scales of the MSLQ. Examination grades were used as the measure of course attainment. Pearson correlations and path analysis revealed that negative affect was positively related to cognitive interference, and positive affect influenced positively the use of almost all of the SRL strategies. Elaboration was the only SRL strategy found to predict the didactics of mathematics course attainment. Finally, cognitive interference was found to negatively predict course attainment.
\end{abstract}

\section{Introduction}

Self-regulated learning (SRL) is a notion that emphasizes the active role of the learner in setting one's goals to learning and ensuring that the goals set is attained [1-4]. Self regulated learning in academic settings is assumed to consist of skills that are learned, rather than being unchangeable or genetically rooted [2]. As a result, various aspects of SRL have often been conceived as being situational and context dependent, while less attention has been devoted to the connection between SRL and individual trait-like characteristics $[5,6]$.

It is generally accepted in SRL research that self-regulation comprises different systems and processes that monitor and control behavior, such as cognition, metacognition, motivation, affect, and volition $[1,7,8]$. According to Efklides [1] and Winne [3] the interactions between different components of SRL can be described either at a macrolevel or at a microlevel. The level of functioning of SRL processes is important because metacognition, motivation, and affect at a macro-level are represented by relatively stable or traitlike person characteristics (e.g., metacognitive knowledge, positive and negative affect, ability beliefs, etc.) [2] that function across tasks or situations. In other words, SRL is conceived as domain-specific but at a generalized level (e.g., self-efficacy in mathematics, emotions raised in a specific course, etc.) rather than at the task-specific or micro-level. The macrolevel, or "Person" level according to Efklides [1], comprises cognitive, metacognitive, motivational, affective, and volitional person characteristics. In extant research in SRL there has been a lot of emphasis on motivational person characteristics but less so on affective. The "metacognitive and affective model of self-regulated Learning" (the MASRL model) [1] posits that there are interrelations between person characteristics and between them and micro-level processes as well. Specifically, affect and motivation are assumed to interact with metacognition, both metacognitive knowledge (MK) and metacognitive strategies (MSs).

Taking into account that there is no exhaustive list of affective person characteristics in the MASRL and that, 
despite the remarkable progress in the concept of selfregulated learning, there are still several unanswered questions about the role of affect (general moods and specific emotions), which — with the exception of test anxiety [9]is not yet fully comprehensible $[10,11]$, this study conceptualized affect in terms of positive affect, negative affect, and cognitive interference (as one of the cognitive components of test anxiety). Focusing on affect is important because there is a need to clarify its role in SRL.

The interest in this study was also in SRL in terms of the proposed model by Pintrich [12] of self-regulated learning comprising three general categories of strategies: cognitive learning strategies, metacognitive control or selfregulatory strategies, and resource management strategies like managing and controlling one's own time, effort, study environment, and so forth. The importance of academic selfregulation is well established in college students, since it has been shown that self-regulated learners' attributes are positively related to their academic achievement and their quality of learning [13-15].

In the following positive affect, negative affect, and cognitive interference are considered in more detail and findings concerning their relations with SRL strategies and performance in academic contexts are reviewed. An empirical study is then reported that tested the interrelations between trait positive affect, trait negative affect, state test anxiety (state cognitive interference), self-reported strategy use, and course attainment in the didactics of mathematics (mathematics teaching) in a School of Early Childhood Education student sample.

1.1. Positive and Negative Affect. Different emotions and moods often compose the more general constructs of positive affect (PA) versus negative affect (NA) as in recent research these two broad and largely uncorrelated factors have emerged reliably as the dominant dimensions of emotional experience [16]. They also emerge consistently across diverse descriptor sets, time frames, response formats, languages, and cultures [17]. As regards the question whether it is appropriate to regard the constructs of PA and NA as relatively independent, Watson et al. [16] have reported low to moderate correlations between the Positive Affect and the Negative Affect Scales of the 20-item Positive and Negative Affect Schedule (PANAS), ranging from -.12 to -.23 , with other studies reporting similar results [18]. Moreover, using CFA, two nearly orthogonal dimensions of positive affect and negative affect were reported for a 10-item short form of the PANAS $(r=-.10)$ as well as for the 20-item form of the PANAS ( $r=-.30)$ [18]. Although, to date, only few studies involving the 20-item PANAS in nonclinical samples have employed CFA, the results from the CFA modeling are consistent with the results of the of EFA and have shown that the positive affect and the negative affect are distinct and largely independent dimensions [19].

In most prior research on achievement goals and emotions, these more general constructs have been used, with PA being measured as an omnibus variable comprising emotions such as enjoyment, pride, and satisfaction, and NA as an omnibus variable comprising emotions such as anxiety, frustration, and sadness [2, 17].

\subsubsection{Affect, Learning Strategies, and Academic Achievement.} In spite of the limited research, there are some findings about the ways affect is involved in self-regulation. First of all, affective factors suit the individual's ability to orientate themselves towards the goals' accomplishment process [11]. In other words affect plays a guiding and regulatory role in our cognitive, as well as in our motivational system [10]. In addition, affect may increase or decrease working memory load by using cognitive resources that could be devoted to the academic task. Emotion has also been used less in mathematics education research, and, despite the different approaches in mathematics education, there is some measure of agreement: emotions affect cognitive processing in several ways. They bias attention and memory. They activate action tendencies and are seen to be functional, with a key role in human coping and adaptation [20].

There are two research trends which support that students' emotions influence academic achievement [10]. Particularly, the experimental mood research has shown that affective states influence cognitive and motivational processes relevant to cognitive achievement. Specifically, it has been found that moods and emotions make the moodcongruent memory processes easier [21] that is, positive affect can increase motivation to approach tasks, while negative affect can increase the mood-congruent avoidance motivation.

Furthermore, emotions can affect some of the selfregulation constituents, such as the selection of a strategy [11]. In particular, in the frame of the experimental mood research, there are findings supporting that negative affect may lead to more analytical, detailed, careful, and inflexible ways of processing information, whereas positive affect promotes the creative, flexible, and holistic way of thinking which has more beneficial effects for more heuristic processing $[10,22,23]$.

However, a significant restriction of the above research is the fact that most of it has focused on attitudes and social judgments and not on the academic content of learning. Surely, there is a second research trend which attempts to analyze students' emotions in academic situations. Yet, most of the research of this trend has concentrated on test anxiety [9] and has shown that anxiety hinders achievement in complex or difficult tasks which call for available cognitive resources. This is due to the fact that affective factors-and consequently test anxiety - can increase or decrease, accordingly, the load of the working memory when they consume available cognitive resources, which could be used in the solution of academic tasks. According to a large number of data, when test anxiety is high, it actually influences learning and achievement negatively, along different age groups and academic fields [24] and the existence of this influence is also reinforced in the mathematics domain [25-30].

Students studying science are also not exempt from the negative effects that test anxiety can have on achievement. Garcia [31] and Obrentz [32] reported that by the end of a semester test anxiety negatively predicted final course grades 
in chemistry. In a study with undergraduates that included biology students, Lin et al. [33] found that those who earned the highest final course grades had low test anxiety. Finally, in a large study with 4.000 undergraduate including nearly $22 \%$ science majors, Chapell and his colleagues [34] found a significant negative relationship between test anxiety and college GPA.

The negative relation between anxiety and academic achievement has been also verified in Pekrun and his colleagues' research $[35,36]$, who looked into the relationships of specific test emotions with academic achievement. Research about the relation of emotions, apart from anxiety, with achievement is limited. Although the relation between general positive affect and achievement is found to be rather inconsistent [37], specific positive test emotions are found to affect achievement in a positive way $[28,35]$, due to the fact that they reinforce motives, strategy use, cognitive resources, and self-regulation.

The relations between negative affect and achievement happen to be more complex, since except for the negative connection of the general negative affect with achievement $[35,36,38]$ and the low, but significant, negative effect of the general negative affect on self-regulated learning strategies [39], especially anxiety has been found to be positively related to the self-reported use of rehearsal $[35,36]$.

\subsection{Cognitive Interference as a Cognitive Facet of Test Anxiety.} Emotion constructs can be linked to momentary emotional episodes and moods or to dispositional tendencies of experiencing momentary emotions and moods. The terms trait emotions and trait affectivity are used to signify dispositional tendencies of the individual towards the experience of either specific emotions or even positive versus negative emotions in general $[35,36]$. From this perspective, to say someone is a test-anxious person implies that he or she has a tendency to see the testing situation in a manner that generally results in feeling anxious. On the other hand, state test anxiety refers to the momentary context-specific appraisals, emotions, and strategies that emerge during a person-environment transaction [11].

Test anxiety is a multidimensional construct that consists of cognitive, affective, and behavioral components. Each facet is construed as representing a distinct response channel through which test anxiety may be expressed to test taking situations. Worry, self-preoccupation, and cognitive interference compose the cognitive facet of test anxiety [9]. Cognitive interference refers to intrusive thoughtsthoughts that are unwanted, undesirable, and disturbing.

Although intrusive thoughts can occur in almost any kind of situation, the bulk of research on cognitive interference has examined their role in test taking situations [40]. Intrusive thoughts occurring in academic situations are hypothesized to be a function of test anxiety and these thoughts can disrupt task performance in anxious individuals. Cognitive interference gets in the way of effective performance because it is the opposite of cognitive accessibility. It diminishes attention to the task the individual is performing [41]. Cognitive interference refers to thoughts that intrude and pop into one's mind during exams, but have no functional value in solving the cognitive task at hand. When high-test-anxious subjects are confronted with difficult or challenging tasks, they are prone to experiencing interfering cognitive responses, dividing attention between the self and the task. Therefore, researchers who study cognitive interference face the challenge of discriminating between on- and off-task thoughts-thoughts which reflect task involvement and are directed towards task completion and thoughts which are not [40]. In addition to being distracted by task-irrelevant thoughts, test anxious students may also be distracted by task-generated thoughts and other irrelevant task-related parameters (e.g., time left to complete exam, task difficulty, level of ability).

\subsubsection{Cognitive Interference and Academic Achievement.} However, all types of thoughts do not have the same effects. Task-related worries, when have been measured as state cognitive interference, are more predictive of performance than are task-irrelevant thoughts. This is consistent with other evidence demonstrating that generalized tendencies to have task-related worries are negatively related to task performance under test-like conditions. This relationship has been found to vary as regards its strength and to be, either direct, or indirect between task-related worries, measured as state cognitive interference, and performance on mathematics' tasks $[9,26,27,40]$. As test-anxious examinees become preoccupied with task irrelevancies, they may employ less efficient strategies with which to solve the task at hand.

Furthermore, there is some research evidence that task generated interference is positively related to test anxiety scores [9]. Often test-anxious students at all levels of education perform more poorly on standardized tests and receive poorer grades [34] than the grades they ought to because anxiety and other test-taking deficiencies interfere with their performance, either directly or indirectly. These effects of test anxiety and cognitive interference on achievement have been confirmed in math problem solving as well [26, 27, 42].

1.2.2. Cognitive Interference and Negative Affect. Research has shown that task-irrelevant thoughts are also highly correlated with negative affect $[38,39]$. According to the resource allocation theory proposed by Ellis and Ashbrook [43], negative affect leads to the increase of task-irrelevant thoughts, which overload working memory, thereby reducing the available cognitive capacity [38].

To sum up, given the emphasis of the resource allocation model in both negative affect and task-irrelevant thoughts, there is a good reason to expect that negative affect as trait can predict cognitive interference as state in the mathematics teaching course attainment in university. Furthermore, the question is if the effects of negative affect on performance are, firstly, distinct and, secondly, mediated by task-irrelevant thoughts.

1.3. Self-Regulated Learning Strategies and Achievement in Mathematics. Self-regulation as an event suggests that selfregulated learning unfolds within particular contexts and 
that associations between SRL (cognitive, metacognitive, and resource management) strategy use and achievement vary with respect to subject area and should therefore be studied at the course level, that is, for an individual discipline or study subject $[44,45]$. Pintrich [2] stated that there is no selfregulatory strategy working equally for all individuals and for all tasks, and according to Duncan and McKeachie [46] students' strategy use depends on the nature of the academic task.

Specifically, the cognitive component of SRL, such as cognitive strategy use, seems to depend on cues of the learning task and environment [47]. Research has shown that mathematics classes were more structured, sequential and less engaging than was the case for social study classes [48]. Mathematics tasks were often cognitively less engaging than the more open-ended and diverse tasks found in social studies. These findings indicate that the context in which the learning task is embedded determines the kind of cognitive strategy that needs to be activated. However, other researchers have reported a significant negative correlation between deep learning strategies (such as organization, elaboration and critical thinking) use and students' final statistics, geometry, and mathematics course grades [49-51]. Furthermore, although high course performers were often found to report using more deep SRL cognitive strategies than low performers, the use of these strategies did not always predict college science course success [29, 32, 52, 53].

Similarly, while students who employ metacognitive and resource management SRL strategies generally perform better academically $[5,6,14,49,54]$, metacognitive strategies were found either to be a moderately negative predictor of achievement in mathematics [50] or not to be significant predictors of science success in courses such as mathematics [29].

As regards the resource management SRL strategies, effort regulation and time and study environment management are two of the most salient predictors of academic achievement $[5,6,14,54]$. Contrary to the aforementioned studies, however, Ozturk et al. [29] found no significant contribution of effort regulation to the variance in high school students' mathematics achievement.

In summary, the literature review regarding SRL strategies reveals an inconsistent pattern of relations of SRL strategy use with achievement in the mathematics subject matter domain. However none of the above studies included mathematics teaching tasks. Thus the question is if SRL strategy use is related to university students' course attainment in the didactics of mathematics subject matter.

1.4. Aim: Hypotheses. The present study aimed to examine the effect of affect (i.e., trait positive affect and trait negative affect) on cognitive interference (i.e., task-oriented worries as state), SRL strategies use (i.e., cognitive, metacognitive, and resource management), and academic performance in university students.

According to the MASRL model [1], interrelations between each of the above person characteristics and the SRL strategies are expected: both positive and negative affects and cognitive interference, as affective characteristics, are assumed to be related to metacognition in the form of metacognitive strategies (MSs) and learning strategies, which constitute the person's usual strategies for the control of cognition and learning.

Specifically, with respect to affect, it was hypothesized that trait positive affect and trait negative affect will be associated with the use of cognitive, metacognitive, and selfregulatory strategies (Hypothesis 1). Based on the studies of Bless et al. [22], Fiedler [23], Malmivuori [28], and Pekrun et al. $[35,36]$, we hypothesized that trait positive affect will be positively associated with the use of learning strategies (Hypothesis 1a); since the relations between negative affect and the SRL strategies happen to be more complex, based on Magno's [39], Pekrun et al.'s [35, 36], and Wolters and Pintrich's [30] findings, we expected either no associations or low negative associations between trait negative affect and use of self-regulated learning strategies, except for the use of lower order cognitive strategies, such as rehearsal, for which we expected their associations with trait negative affect to be positive (Hypothesis 1b).

As trait characteristics are more distal from performance than the use of learning strategies, it was hypothesized that the effects of positive and negative affect on academic performance will be mediated by learning strategies. Specifically, since several studies $[5,32,49]$ have shown that various aspects of each one of the three general categories of SRL strategies (cognitive, metacognitive, and resource management) emerged as good predictors of performance in mathematics, trait positive and negative affects were expected to have an indirect effect on course attainment mediated by use of cognitive, metacognitive, and resource management strategies (Hypothesis 2).

According to Ellis and Ashbrook's [43] resource allocation model and to Linnenbrink et al.'s [38] and Magno's [39] findings, negative affect as a trait was expected to be positively associated with cognitive interference as a state (Hypothesis 3a). As trait characteristics are more distal from performance than state characteristics, we hypothesized that the effects of negative affect on academic performance will be mediated by cognitive interference (Hypothesis $3 \mathrm{~b}$ ).

With respect to cognitive interference as a cognitive facet of test anxiety, it was hypothesized that it will be negatively related to course attainment (Hypothesis 4), either directly [24, 25, 28-30] (Hypothesis 4a) or indirectly [25-27] via learning strategy use $[1,9]$ (Hypothesis $4 \mathrm{~b}$ ).

Finally, based on the studies of Crawford and Henry [18], Tellegen et al. [19], and Watson et al. [16], we expected either no associations or low negative associations between the distinct constructs of positive affect and negative affect (Hypothesis 5).

\section{Method}

2.1. Participants. The sample consisted of 180 undergraduate students (6 male, 174 female, mean age $=21.1$ years, SD $=2.3$ ) attending a didactics of mathematics course at the School of Early Childhood Education at the University of Ioannina in Greece. Participation in the study was voluntary 
and $78.26 \%$ of the students in the course participated in the study.

\subsection{Instruments}

2.2.1. The Positive and Negative Affect Schedule (PANAS). The PANAS [16] is a self-report questionnaire which consists of two 10-item scales for positive affect and negative affect, respectively. For the purposes of a previous study the PANAS was translated into Greek and tested for its construct validity by Moraitou and Efklides [55]. Participants had to answer to what extent in general they feel what was described by each item. Responses were on a Likert-type scale from 1 (very few times or not at all) to 5 (too many times).

The internal consistency for the two factors of PANAS, namely, Trait Positive Affect and Trait Negative Affect, was satisfactory: Cronbach's $\alpha=.81$ and .86 , respectively.

2.2.2. The Cognitive Interference Questionnaire (CIQ). The CIQ [41] provides an index of intrusive thinking in a specific situation and consequently it might be regarded as a state measure of cognitive interference. The CIQ is a 22-item questionnaire designed to measure, following performance on a task, the degree to which people experienced various types of thoughts while working on it, and the degree to which these thoughts are viewed as interfering with concentration. According to its constructors [41], the CIQ measures two types of thoughts, task-oriented worries and off-task thoughts. The task-oriented worries dimension was used in the present study. Participants were asked to indicate the frequency of occurrence of task-related thoughts that intruded while they were working on their examination in the didactics of mathematics course on a 5-point scale from 1 (never) to 5 (very often). Cronbach's $\alpha$ was acceptable: .77 .

For the purposes of a previous study, the first 10 items of the CIQ, providing post-performance reports of the frequency of occurrence of task-oriented worries, had been translated into Greek by the first author and the single factor structure of the Greek version of the task-oriented worries dimension of the CIQ was verified with CFA [56].

2.2.3. The Motivated Strategies for Learning Questionnaire (MSLQ). The MSLQ was developed by Pintrich et al. [57] as a measure of self-regulated learning. The MSLQ has two sections, a motivational and a learning strategies section. In this study the learning strategies section was used to assess college students' use of various learning strategies in college courses. The learning strategies section of the MSLQ consists of 50 items, divided into nine subscales measuring: rehearsal, elaboration, organization, and critical thinking (representing the cognitive aspect of self-regulated learning); metacognition (representing the metacognitive aspect of self-regulation); and environment and time management, effort regulation, peer learning, and help seeking (representing the management component of self-regulation). Responses are given on a 7point Likert-type scale anchored by 1 (not at all true of me) and 7 (very true of me). An example from the subscale used to measure elaboration is "when reading for this class, I try to relate the material to what I already know." An example from the subscale used to measure metacognition is "when I study for this class, I set goals for myself in order to direct my activities in each study period." An example from the subscale used to measure study environment management is "I usually study in a place where I can concentrate on my course work."

For the purposes of a previous study the learning strategies section of MSLQ was translated into Greek by two of the authors and an independent bilingual person. The two versions of the translated questionnaire were then compared and modifications were made. Confirmatory factor analysis verified the nine-factor structure of the Greek version of the learning strategies section of MSLQ [6].

Cronbach's alphas, for the sample of the present study, were also comparable to those of Pintrich et al. [57] (given in parenthesis): $\alpha=.56$ (.69) for rehearsal, $\alpha=.68(.76)$ for elaboration, $\alpha=.76(.64)$ for organization, $\alpha=.65(.80)$ for critical thinking, $\alpha=.69$ (.79) for metacognition, $\alpha=.75$ (.76) for environment and time management, $\alpha=.76(.69)$ for effort regulation, $\alpha=.68$ (.76) for peer learning, and $\alpha=.57$ (.52) for help seeking.

2.2.4. Course Attainment. Course attainment in the didactics of mathematics was measured with students' final course grade, which was converted to a 10 -point scale $(M=4.62$; $\mathrm{SD}=2.30$ ). Final course grade was assessed with (a) an essay (maximum score: 3 ) and (b) an exam, which required recall of information from textbooks and was administered at the end of the semester (maximum score: 7).

2.3. Procedure. Institutional permission for conducting research with human subjects was obtained. All participants gave informed consent, they were assured confidentiality, and they were provided code numbers in order their anonymity to be preserved. Questionnaires were administered in the classroom. The PANAS was administered at the beginning of the semester. Participants also provided demographic information, including age, gender, and class level prior to completing the questionnaire. The MSLQ was administered during a session at the end of the semester, while the CIQ was administered after their final examination in the didactics of mathematics course.

2.4. Statistical Analyses. In order to examine the relationships between the various constructs of the study, Pearson correlations were computed in addition to the use of path analysis-a structural equation modeling (SEM) technique for analyzing structural models with observed variables. Sum scores were used for the various scales. Specifically, to examine the model depicting the hypothesized relationships between the subscales of positive and negative affects, cognitive interference, SRL strategies, and course attainment in didactics of mathematics, a path analysis with manifest variables was computed. Although it is undoubtedly true that the attainment of specific goals (e.g., passing an exam) may enhance one's level of trait positive affect and trait negative affect, the general rule is that personality traits are 
relatively enduring, and so when an association is found between a trait (such as positive and negative affect) and a specific behavior (such as reaching one's goal), it is plausible to assume that the trait caused the behavior rather than the other way round. Consequently, the two components of affect were treated as trait-like variables, while the graded performance, the state cognitive interference, and the nine self-regulated learning strategies were treated as domainspecific variables.

Path analysis was conducted in EQS Version 6.1 and performed on covariance matrix using the Maximum Likelihood estimation procedure [58]. Initially, in the structural part of the model, the two affective independent variables incorporated in the path model were allowed to correlate between them and predict the nine latent variables of selfregulated learning strategies, the cognitive interference, and the dependent variable of course attainment. Simultaneously, the latent self-regulation learning strategies variables and the cognitive interference were allowed to correlate and predict the dependent variable of course attainment as well. Modifications suggested by the Wald test were used to test the necessity of the regressions included in the model and to ensure a theoretically plausible and statistically restricted model. The chi-square $\left(\chi^{2}\right)$, the chi-square/degrees of freedom $\left(\chi^{2} / d f\right)$ ratio, the Comparative Fit Index (CFI), the standardized root mean squared residual (SRMR), and the root mean squared error of approximation (RMSEA) were used as indices of the model.

\section{Results}

Correlation matrix between positive and negative affect, cognitive interference, SRL strategies, and mathematics teaching course attainment is shown in Table 1.

The path model that was confirmed is displayed in Figure 1. The dotted lines indicate the direct effects of the domain specific variables on course attainment. The overall fit of the model was good, $\chi^{2}(33, N=173)=34.31, P=$ $.40, \chi^{2} / d f=1.04, \mathrm{CFI}=1.00, \mathrm{SRMR}=.05$, and RMSEA $=$ $.02\left(\mathrm{CI}_{90 \%} .00\right.$ to .06) [59].

As hypothesized in (H1) and (H1a), trait positive affect was related to the use of several cognitive, metacognitive, and resource management strategies. Specifically, it was positively related to the use of all of the cognitive, metacognitive, and resource management strategies, except for critical thinking. That is, the higher the trait positive affects the more the use of the SRL strategies.

Furthermore, since all of the cognitive, metacognitive, and resource management strategies, except for rehearsal and peer seeking, were positively correlated with course attainment, it seems that a student's trait positive affect could be beneficial to performance (H2). However, this noteworthy finding of Pearson correlations was not observed in path analysis where elaboration was the only SRL strategy found to be positively related to course attainment (explained variance: $11-12 \%)(\mathrm{H} 2)$.

Contrary to (H1) and (H2), trait negative affect was not related, either directly to the SRL strategy use, or indirectly to performance via regulation of the use of SRL strategies. It seems that trait negative affect neither facilitates nor inhibits the SRL strategy use in the mathematics teaching subject matter domain (H1b).

As hypothesized in (H3a) and (H3b), trait negative affect was positively related to cognitive interference and, through this, negatively to course attainment. It seems that a student's trait negative affect explains state cognitive interference (the degree to which a student experienced task-oriented worries, while working on the examination tasks, and the degree to which these thoughts are viewed as interfering with concentration) (explained variance: 18-19\%), which in turn is translated into lower graded performance.

As hypothesized in (H4a) state cognitive interference was found to be directly and negatively related to course attainment (explained variance: $4 \%$ ). Contrary to (H4b), however, cognitive interference was not found to be indirectly related to performance via regulation of the use of SRL strategies, since, except for a positive correlation with rehearsal, there was a lack of relationships between SRL strategies and taskoriented worries.

Finally, as hypothesized in (H5), no association was found between positive and negative affects. This finding is consistent to the PANAS constructors' findings that positive affect and negative affect are distinct and largely independent dimensions of the instrument.

\section{Discussion}

The aim of this study was to examine the effect of prospective kindergarten teachers' affect and cognitive interference on their SRL strategy use and academic performance in a didactics of mathematics course. The present study focused on three of the students' characteristics, namely, positive affect, negative affect, and cognitive interference as affective constructs, and their potential impact on self-regulated learning. Specifically, this study found that SRL strategies and course attainment are linked to important trait-like characteristics, such as trait positive and trait negative affect, and domain-specific characteristics, such as state cognitive interference.

Without discounting the claim that SRL skills, in general, are learnable, the results of the present study suggest that personality predispositions impact SRL strategy use and academic achievement in specific situations $[1,5]$. Affect and cognitive interference can lead to decisions regarding topdown self-regulation as both of them appear to be associated with metacognitive knowledge in the form of strategies (the SRL cognitive, metacognitive and resource management strategies) that one tends to use when dealing with a task (e.g., a didactic of mathematics course examination essay) [1]. These findings are in accordance with the MASRL model's predictions for the person characteristics and support the importance of affective factors in self-regulated learning.

4.1. Effects of Positive Affect on SRL Strategy Use and Course Attainment. As regards the predictive ability of positive and 


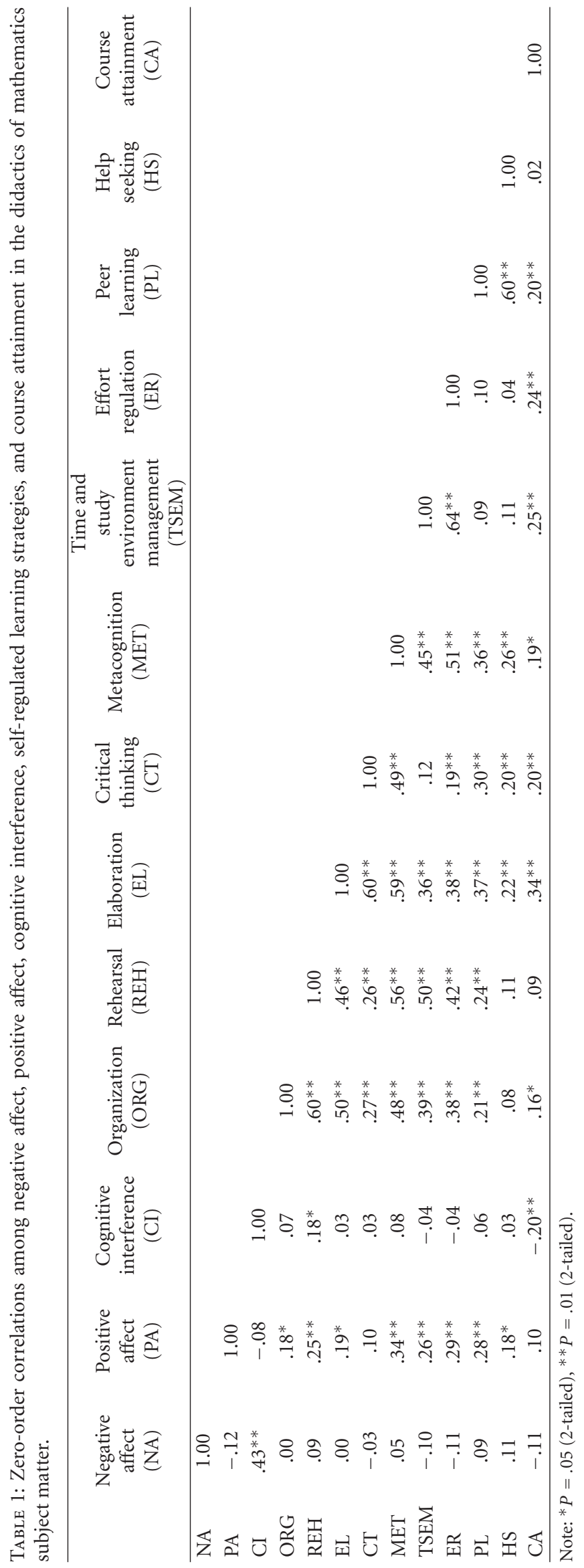




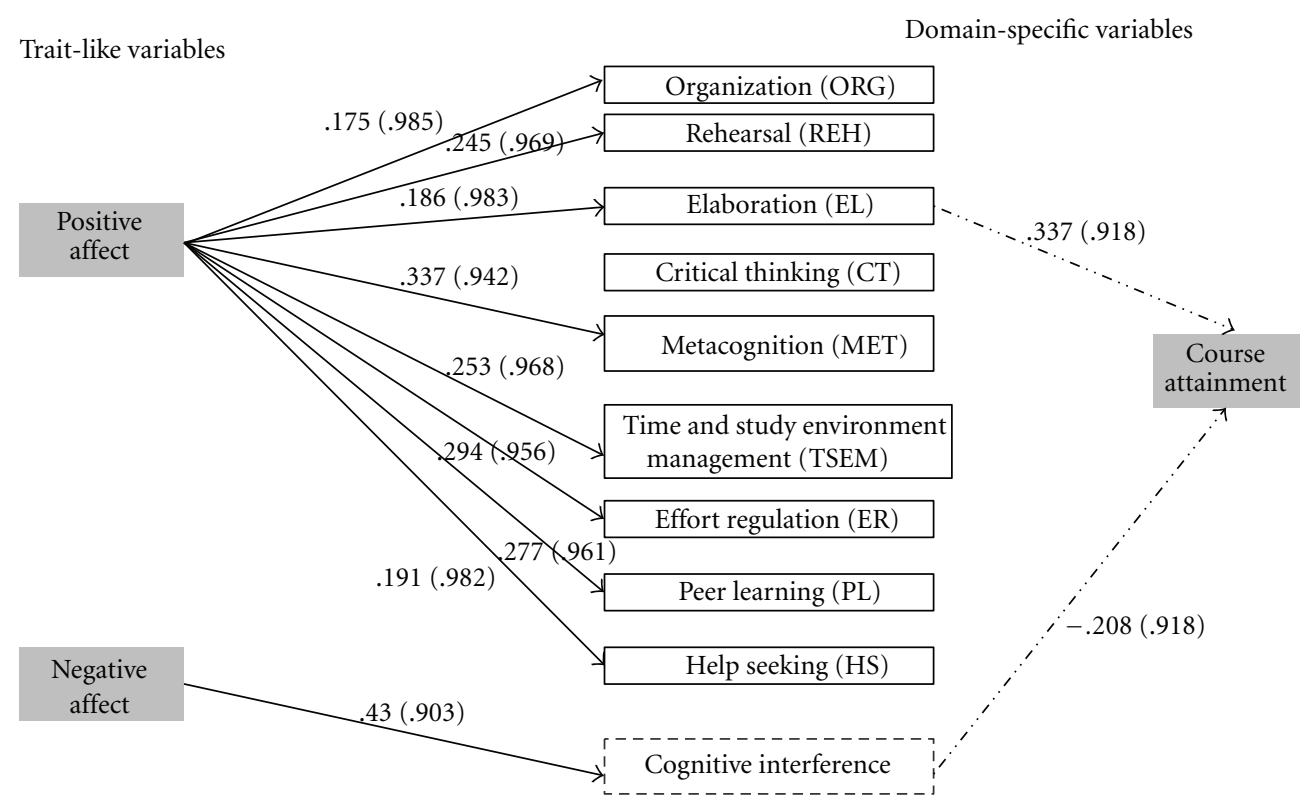

FIGURE 1: The final path model displaying the relationships among negative affect, positive affect, cognitive interference, self-regulated learning strategies, and course attainment in the didactics of mathematics subject matter. Note 1. All paths drawn indicate significant associations $(P<.05)$. Note 2. Doted lines indicate direct effects on course attainment. Note 3. Errors are given in parenthesis. Note 4. Correlations of SRL strategies: REH-ORG: .584, EL-ORG: .475, MET-ORG: .450, TSEM -ORG: .362, ER-ORG: .338, PL-ORG: .148, ELREH: .417, MET-REH: .495, TSEM -REH: .465, ER-REH: .344, PL-REH: .137, MET-EL: .567, TSEM -EL: .316, ER-EL: .331, PL-EL: .313, HS-EL: .175, TSEM -MET: .400, ER-MET: .448, PL-MET: .276, HS-MET: .206, ER-TSEM : .619, HS-PL: .588.

negative affect for SRL strategy use, positive affect clearly stands out as a powerful predictor. Specifically, positive affect was found to positively affect the use of the most cognitive, metacognitive, and resource management strategies in the didactics of mathematics subject matter domain. It seems that students who have positive affect are likely to employ more a variety of self-regulated learning strategies in order to learn new and advanced material and apply concepts to problem solving and scientific inquiry in a didactics of mathematics undergraduate course compared to their counterparts lacking positive affect.

Since elaboration-which is a higher order cognitive strategy - was found to be positively associated with course attainment in mathematics teaching, the above finding is consistent with the literature showing that positive affect benefits students' achievement in a significant test, such as a test in the didactics of mathematics course, reinforcing the effective use of self-regulated learning strategies [28, 35, 36]. Therefore, the encouraging effect of the positive affect on the SRL strategy use should be taken into account at the interventions planned to teach college students to be selfregulated learners.

\subsection{Effects of Negative Affect on SRL Strategy Use and Course} Attainment. Contrary to positive affect, negative affect was not found to be associated with any SRL strategy use. Since in the present study the negative affect was appointed as a general variable, which consists of emotions such as anxiety, frustration-which is one of the reasons of angerand shame, its influence on performance, via the use of
SRL strategies, was found to be neutral. These findings are reinforced by Pekrun et al.'s $[35,36]$ opinion who claims that the influence of anger and shame on achievement, as well as the effect of anxiety [9], does not always need to be negative. It may be proved neutral or even positive for achievement in some projects, for specific individuals and under specific circumstances.

4.3. Effects of SRL Strategy Use on Course Attainment. Although almost all of the SRL strategies were found to be positively correlated with mathematics teaching graded performance, elaboration was the only SRL strategy found to predict it. This finding is consistent with previous research indicating that although high course performers were often found to report using more deep SRL cognitive strategies (such as organization, elaboration, and critical thinking) than low performers $[60,61]$, the use of these strategies did not always predict college science course success $[29,32,52$, 53].

It seems that early childhood education students who tend to paraphrase and summarize effectively the learning material are likely to perform better in a didactics of mathematics undergraduate course compared to their counterparts lacking these qualities. In addition, the finding that elaboration was the only SRL strategy predicting graded performance in the didactics of mathematics course is possible to be due to the composition of the sample, as regards gender, as $97,7 \%$ of the participants were female students. Wolters and Pintrich [30] demonstrated that while academic success and self-regulatory (metacognitive) strategy use were 
similar in mathematics, social sciences, and English for both male and female, female students employed higher levels of cognitive strategy use than male students in all three subject areas. These findings can be associated with test anxiety: students with higher levels of test anxiety were more likely to employ cognitive strategies but less likely to employ selfregulatory (metacognitive) strategies and more likely to get lower scores [30]. Similarly, students who participated in the present study employed higher level of elaboration; they got rather low final course grade (converted to a 10-point scale, $M=4.62$ ) and their course attainment was found to be negatively predicted by state cognitive interference (explained variance: $4 \%$ ).

This finding might indicate that female students, who compose the majority at the Greek Early Childhood Education Schools, lack the skills needed to be able to be themselves self-regulated learners (the learner's perspective in SRL) in the didactics of mathematics subject matter. Therefore, as preservice kindergarten teachers, it is possible that they will continue to lack the skills and knowledge needed to be able to teach mathematics successfully and to understand how to help their students achieve SRL (the teacher's perspective in SRL) $[62,63]$. Since the ability to self-regulate learning is highly useful for preservice teachers' professional growth during their entire career and for promoting these processes among students $[62,63]$, the above indication reinforces Kramarski's and Michalsky's [63] suggestion that teachers' SRL may be developed through participation in training programs that provide opportunities to the teachers to control their learning and, consequently, their teaching.

4.4. Relations between Negative Affect and Cognitive Interference. An interesting finding of the present study concerns the positive relationship of trait negative affect with state cognitive interference. As it has already been mentioned, negative effect as disposition has been appointed and measured as a general variable, which includes emotions such as anxiety and frustration $[2,35,36]$. Seeing that state cognitive interference as a cognitive facet of test anxiety is appointed as instant emotional state, experienced before or during a particular test [9], it is presumable that a great part of its variance is explained by more general dispositions such as the trait negative affect and/or test anxiety as personality characteristic. Furthermore, the specific finding, as well as the finding of the indirect (through state cognitive interference) negative effect of trait negative affect on attainment in the didactics of mathematics course, falls within the frame of the resource allocation theory [43], according to which trait negative affect leads to the increase of intrusive thoughts, which overload working memory, decreasing the available cognitive resources $[35,36,38]$.

To conclude, except for the aforementioned direct effect of state cognitive interference on the didactics of mathematics course attainment, the present study also reveals a lack of relations between SRL strategies and cognitive interference, except for a low correlation $(r=.18)$ of cognitive interference with rehearsal, which is reinforced by Pekrun's $[35,36]$ opinion who claims that the effect of anxiety [9], does not always need to be negative. It may be proved neutral or even positive for achievement in some projects, for specific individuals and under specific circumstances. Moreover, even in the frame of the experimental research for moods, there are findings which support that negative affect can lead to more analytical, detailed, but also inflexible ways of processing data, such as the lower order strategy of rehearsal.

Generally speaking, the lack of relations between SRL strategies and cognitive interference is consistent to the cognitive-attentional (interference) model, which associates test anxiety with deficits in retrieval of previously learned information [9].

4.5. Limitations of the Study. A limitation of this study is the less validity of the used self-report measure of self-regulatory skills, since the MSLQ does not accurately measure the participants' actual use of SRL strategy. Selfregulated data collected during learning is a more accurate measurement of processes related to SRL $[64,65]$. Thus, more rigorous designs are needed to establish the validity of the relationship between academic self-regulation and trait-like characteristics using behavioral and observational measures of self-regulation (i.e., real-time measurements of learning strategies, think-aloud protocol data, or videobased assessment of strategy use) [66, 67]. The restricted nature of the sample should also be noted, especially with regard to age and gender. It is also not known whether the same pattern of results would be obtained, if college students of other disciplines, other than early childhood education, were involved.

In conclusion, our findings suggest that affect as general disposition influences in distinct ways students' SRL strategy use and course attainment in the didactics of mathematics subject matter domain. Future research should further clarify, in different college student groups and in different age groups, how affective factors predispose individuals to employ SRL (how affective factors encourage or discourage individuals to become self-regulating learners) and how these dispositions interact with learning situations in developing relevant self-regulation strategies. It will also be helpful for future research to examine the variety of specialized emotions, such as hope, pride, anger, and shame, which arouse in the academic environment, and to evaluate the role that they may play in self-regulated learning.

\section{References}

[1] A. Efklides, "Interactions of metacognition with motivation and affect in self-regulated learning: the MASRL model," Educational Psychologist, vol. 46, no. 1, pp. 6-25, 2011.

[2] P. R. Pintrich, "The role of goal orientation in self-regulated learning," in Handbook of Self-Regulation, M. Boekaerts, P. R. Pintrich, and M. Zeidner, Eds., pp. 451-502, Academic Press, San Diego, Calif, USA, 2000.

[3] P. H. Winne, "Students' calibration of knowledge and learning processes: implications for designing powerful software learning environments," International Journal of Educational Research, vol. 41, no. 6, pp. 466-488, 2004. 
[4] B. J. Zimmerman, "Investigating self-regulation and motivation: historical background, methodological developments, and future prospects," American Educational Research Journal, vol. 45, no. 1, pp. 166-183, 2008.

[5] T. Bidjerano and D. Y. Dai, "The relationship between the bigfive model of personality and self-regulated learning strategies," Learning and Individual Differences, vol. 17, no. 1, pp. 69-81, 2007.

[6] G. Papantoniou, D. Moraitou, E. Katsadima, and M. Dinou, "Action control and dispositional hope: an examination of their effect on self-regulated learning," Electronic Journal of Research in Educational Psychology, vol. 8, no. 1, pp. 5-32, 2010.

[7] J. Kuhl and A. Fuhrmann, "Decomposing self-regulation and self-control: the volitional components inventory," in Motivation and Self-Regulation Across the Life Span, J. Heckhausen and C. S. Dweck, Eds., pp. 15-49, Cambridge University Press, New York, NY, USA, 1998.

[8] B. J. Zimmerman, "Commentary: toward a cyclically interactive view of self-regulated learning," International Journal of Educational Research, vol. 31, no. 6, pp. 545-551, 1999.

[9] M. Zeidner, Test Anxiety: The State of Art, Plenum Press, New York, NY, USA, 1998.

[10] P. R. Pintrich, "A motivational science perspective on the role of student motivation in learning and teaching contexts," Journal of Educational Psychology, vol. 95, no. 4, pp. 667-686, 2003.

[11] P. A. Schutz and H. A. Davis, "Emotions and self-regulation during test taking," Educational Psychologist, vol. 35, no. 4, pp. 243-256, 2000.

[12] P. R. Pintrich, "The role of motivation in promoting and sustaining self-regulated learning," International Journal of Educational Research, vol. 31, no. 6, pp. 459-470, 1999.

[13] M. Boekaerts, "Self-regulated learning: a new concept embraced by researchers, policy makers, educators, teachers, and students," Learning and Instruction, vol. 7, no. 2, pp. 161$186,1997$.

[14] P. R. Pintrich and E. V. De Groot, "Motivational and self-regulated learning components of classroom academic performance," Journal of Educational Psychology, vol. 82, no. 1, pp. 33-40, 1990.

[15] D. H. Schunk and B. J. Zimmerman, Self-Regulation of Learning and Performance, Erlbaum, Hillsdale, NJ, USA, 1994.

[16] D. Watson, L. A. Clark, and A. Tellegen, "Development and validation of brief measures of positive and negative affect: the PANAS scales," Journal of Personality and Social Psychology, vol. 54, no. 6, pp. 1063-1070, 1988.

[17] D. Watson and L. A. Clark, The PANAS-X: Manual for the Positive and Negative Affect Schedule-Expanded Form, The University of Iowa, 1994.

[18] J. R. Crawford and J. D. Henry, "The Positive and Negative Affect Schedule (PANAS): construct validity, measurement properties and normative data in a large non-clinical sample," British Journal of Clinical Psychology, vol. 43, no. 3, pp. 245265, 2004.

[19] A. Tellegen, D. Watson, and L. A. Clark, "On the dimensional and hierarchical structure of affect," Psychological Science, vol. 10, no. 4, pp. 297-303, 1999.

[20] R. Zan, L. Brown, J. Evans, and M. S. Hannula, "Affect in mathematics education: an introduction," Educational Studies in Mathematics, vol. 63, no. 2, pp. 113-121, 2006.

[21] K. M. Olafson and F. R. Ferraro, "Effects of emotional state on lexical decision performance," Brain and Cognition, vol. 45, no. 1, pp. 15-20, 2001.
[22] H. Bless, N. Schwarz, G. L. Clore, V. Golisano, C. Rabe, and M. Wölk, "Mood and the use of scripts: does a happy mood really lead to mindlessness?" Journal of Personality and Social Psychology, vol. 71, no. 4, pp. 665-679, 1996.

[23] K. Fiedler, "Affective states trigger processes of assimilation and accommodation," in Theories of Mood and Cognition: A User's Guidebook, L. L. Martin and G. L. Clore, Eds., pp. 8598, Erlbaum, Mahwah, NJ, USA, 2001.

[24] R. Hembree, "Correlates, causes, effects, and treatment of test anxiety," Review of Educational Research, vol. 58, pp. 47-77, 1988.

[25] J.-L. Berger, "The influence of achievement goals on metacognitive processes in math problem solving," Journal of Cognitive Education and Psychology, vol. 8, pp. 165-181, 2009.

[26] A. Efklides, M. Papadaki, G. Papantoniou, and G. Kiosseoglou, "Effects of cognitive ability and affect on school mathematics performance and feelings of difficulty," American Journal of Psychology, vol. 110, no. 2, pp. 225-258, 1997.

[27] A. Efklides, M. Papadaki, G. Papantoniou, and G. Kiosseoglou, "Individual differences in school mathematics performance and feelings of difficulty: the effects of cognitive ability, affect, age, and gender," European Journal of Psychology of Education, vol. 14, no. 1, pp. 57-69, 1999.

[28] M. L. Malmivuori, "Affect and self-regulation," Educational Studies in Mathematics, vol. 63, no. 2, pp. 149-164, 2006.

[29] B. Ozturk, S. Bulut, and Y. Koc, "Motivation and selfregulation in mathematics," Academic Exchange Quarterly, vol. 11, no. 1, pp. 149-154, 2007.

[30] C. A. Wolters and P. R. Pintrich, "Contextual differences in student motivation and self-regulated learning in mathematics, English, and social studies classrooms," Instructional Science, vol. 26, no. 1-2, pp. 27-47, 1998.

[31] T. Garcia, "Women and minorities in science: motivational and cognitive correlates of achievement," in Annual Meeting of the American Educational Research Association, Atlanda, Ga, USA, April 1993.

[32] S. B. Obrentz, Predictors of science success: the impact of motivation and learning strategies on college chemistry performance [dissertation], Georgia State University, Atlanta, Ga, USA, 2011.

[33] Y. G. Lin, W. J. McKeachie, and Y. C. Kim, "College student intrinsic and/or extrinsic motivation and learning," Learning and Individual Differences, vol. 13, no. 3, pp. 251-258, 2001.

[34] M. S. Chapell, Z. Benjamin Blanding, M. Takahashi et al., "Test anxiety and academic performance in undergraduate and graduate students," Journal of Educational Psychology, vol. 97, no. 2, pp. 268-274, 2005.

[35] R. Pekrun, T. Goetz, R. P. Perry, K. Kramer, M. Hochstadt, and S. Molfenter, "Beyond test anxiety: development and validation of the Test Emotions Questionnaire (TEQ)," Anxiety, Stress and Coping, vol. 17, no. 3, pp. 287-316, 2004.

[36] R. Pekrun, T. Goetz, W. Titz, and R. P. Perry, "Academic emotions in students' self-regulated learning and achievement: a program of qualitative and quantitative research," Educational Psychologist, vol. 37, no. 2, pp. 91-105, 2002.

[37] E. A. Linnenbrink, "The role of affect in student learning: a multi-dimensional approach to considering the interaction of affect, motivation and engagement," in Emotion in Education, P. A. Schutz and R. Pekrun, Eds., pp. 107-124, Academic Press, San Diego, Calif, USA, 2007.

[38] E. A. Linnenbrink, A. M. Ryan, and P. R. Pintrich, "The role of goals and affect in working memory functioning," Learning and Individual Differences, vol. 11, no. 2, pp. 213-230, 1999. 
[39] C. Magno, "Integrating negative affect measures in a measurement model: assessing the function of negative affect as interference to self-regulation," The International Journal of Educational and Psychological Assessment, vol. 4, pp. 48-67, 2010.

[40] I. G. Sarason, G. R. Pierce, and B. R. Sarason, "Domains of cognitive interference," in Cognitive Interference: Theories, Methods, and Findings, I. G. Sarason, G. R. Pierce, and B. R. Sarason, Eds., pp. 139-152, Erlbaum, Mahwah, NJ, USA, 1996.

[41] I. G. Sarason, B. R. Sarason, D. E. Keefe, B. E. Hayes, and E. N. Shearin, "Cognitive interference: situational determinants and trait-like characteristics," Journal of Personality and Social Psychology, vol. 51, no. 1, pp. 215-226, 1986.

[42] P. Metallidou and A. Vlachou, "Motivational beliefs, cognitive engagement, and achievement in language and mathematics in elementary school children," International Journal of Psychology, vol. 42, no. 1, pp. 2-15, 2007.

[43] H. C. Ellis and P. W. Ashbrook, "Resource allocation model of the effects of depressed mood states on memory," in Affect, Cognition, and Social Behaviour, K. Fiedler and J. P. Forgas, Eds., pp. 25-43, Hogrefe, Toronto, Canada, 1988.

[44] M. Boekaerts, P. Pintrich, and M. Zeidner, Handbook of SelfRegulation, Academic Press, San Diego, Calif, USA, 2000.

[45] D. C. Moos and R. Avezedo, "The role of goal structure in undergraduates' use of self-regulatory variables in two hypermedia learning tasks," Journal of Educational Multimedia and Hypermedia, vol. 15, no. 1, pp. 49-86, 2006.

[46] T. G. Duncan and W. J. McKeachie, "The making of the motivated strategies for learning questionnaire," Educational Psychologist, vol. 40, no. 2, pp. 117-128, 2005.

[47] A. L. Brown, J. D. Bransford, R. A. Ferrara, and J. C. Campione, "Learning, remembering, and understanding," in Handbook of Child Psychology, P. H. Mussen, J. H. Flavell, and E. M. Markman, Eds., vol. 3 of Cognitive Development, pp. 77-166, John Wiley \& Sons, New York, NY, USA, 1983.

[48] S. S. Stodolsky, The Subject Matters: Classroom Activity in Math and Social Studies, University of Chicago Press, Chicago, Ill, USA, 1988.

[49] D. L. Bandalos, S. J. Finney, and J. A. Geske, "A model of statistics performance based on achievement goal theory," Journal of Educational Psychology, vol. 95, no. 3, pp. 604-616, 2003.

[50] N. Mousoulides and G. Philippou, "Students' motivational beliefs, self-regulation strategies and mathematics achievement," in Proceedings of the 29th Conference of the International Group for the Psychology of Mathematics Education, H. L. Chick and J. L. Vincent, Eds., vol. 3, pp. 321-328, PME, Melbourne, Australia, 2005.

[51] P. Pokay and P. C. Blumenfeld, "Predicting achievement early and late in the semester: the role of motivation and use of learning strategies," Journal of Educational Psychology, vol. 82, no. 1, pp. 41-50, 1990.

[52] P. A. Schutz, L. M. Drogosz, V. E. White, and C. Distefano, "Prior knowledge, attitude, and strategy use in an introduction to statistics course," Learning and Individual Differences, vol. 10, no. 4, pp. 291-308, 1998.

[53] S. L. Yu, "Women's motivation and strategy use in college science classes," Journal of Staff, Program, \& Organization Development, vol. 16, pp. 93-101, 1999.

[54] B. E. Brackney and S. A. Karabenick, "Psychopathology and academic performance: the role of motivation and learning strategies," Journal of Counseling Psychology, vol. 42, no. 4, pp. 456-465, 1995.
[55] D. Moraitou and A. Efklides, "The blank in the mind questionnaire (BIMQ)," European Journal of Psychological Assessment, vol. 25, no. 2, pp. 115-122, 2009.

[56] G. Papantoniou, Cognitive style, anxiety and action control [dissertation], Aristotle University of Thessaloniki, Thessaloniki, Greece, 2002.

[57] P. R. Pintrich, D. A. F. Smith, T. Garcia, and W. J. McKeachie, "A manual for the use of the Motivated Strategies for Learning Questionnaire," Tech. Rep., The Regents of the University of Michigan, Ann Arbor, Mich, USA, 1991.

[58] P. M. Bentler, EQS 6.1, Multivariate Software, Encino, Calif, USA, 2005.

[59] T. A. Brown, Confirmatory Factor Analysis for Applied Research, Guilford Press, New York, NY, USA, 2006.

[60] A. Zusho, P. R. Pintrich, and B. Coppola, "Skill and will: the role of motivation and cognition in the learning of college chemistry," International Journal of Science Education, vol. 25, no. 9, pp. 1081-1094, 2003.

[61] P. Zeegers, "Approaches to learning in science: a longitudinal study," British Journal of Educational Psychology, vol. 71, no. 1, pp. 115-132, 2001.

[62] B. Kramarski and T. Michalsky, "Investigating pre-service teachers' professional growth in self-regulated learning environments," Journal of Educational Psychology, vol. 101, no. 1, pp. 161-175, 2009.

[63] B. Kramarski and T. Michalsky, "Preparing preservice teachers for self-regulated learning in the context of technological pedagogical content knowledge," Learning and Instruction, vol. 20, no. 5, pp. 434-447, 2010.

[64] R. Azevedo, "Computer environments as metacognitive tools for enhancing learning," Educational Psychologist, vol. 40, no. 4, pp. 193-197, 2005.

[65] P. H. Winne and N. E. Perry, "Measuring self-regulated learning," in Handbook of Self-Regulation, M. Boekaerts, P. Pintrich, and M. Zeidner, Eds., pp. 531-566, Academic Press, San Diego, Calif, USA, 2000.

[66] J. A. Greene and R. Azevedo, "A macro-level analysis of SRL processes and their relations to the acquisition of a sophisticated mental model of a complex system," Contemporary Educational Psychology, vol. 34, no. 1, pp. 18-29, 2009.

[67] I. Dermitzaki, "Introduction: individual and social processes in the regulation of learning," Hellenic Journal of Psychology, vol. 1, no. 2, pp. 119-127, 2004. 


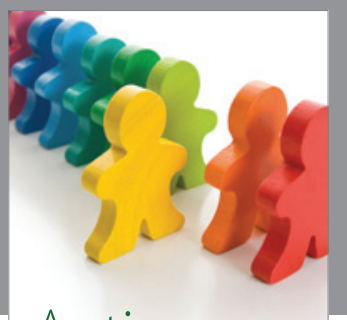

Autism

Research and Treatment
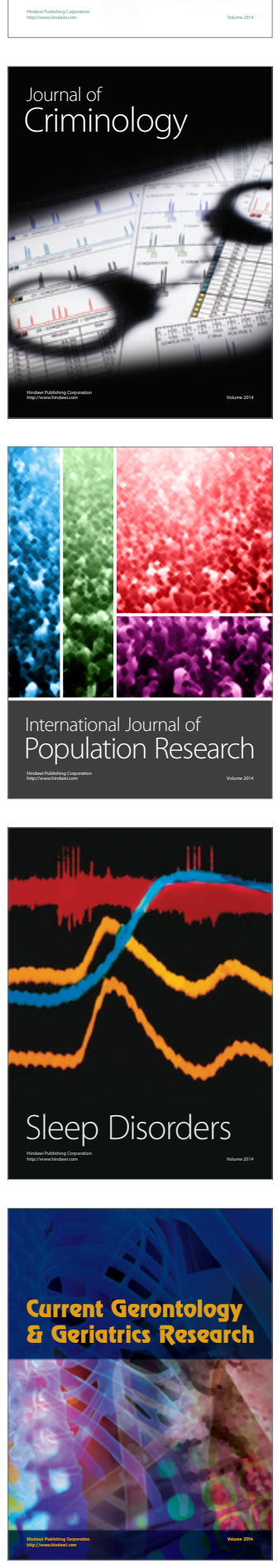
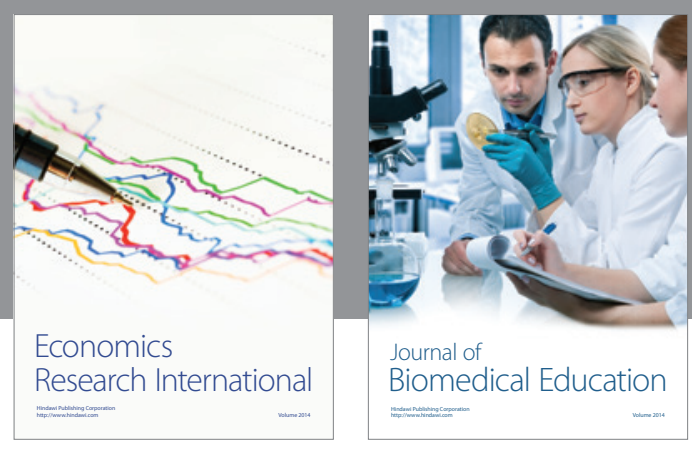

Journal of

Biomedical Education

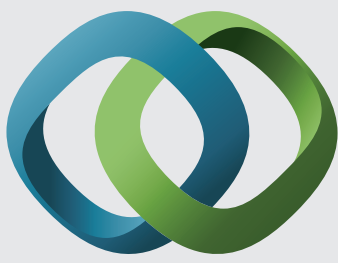

\section{Hindawi}

Submit your manuscripts at

http://www.hindawi.com
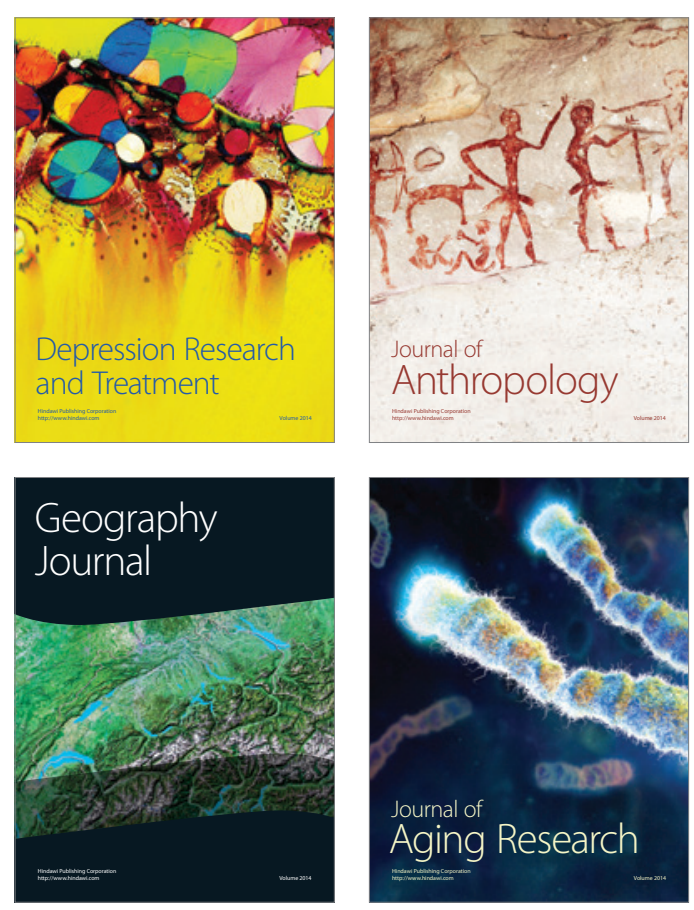

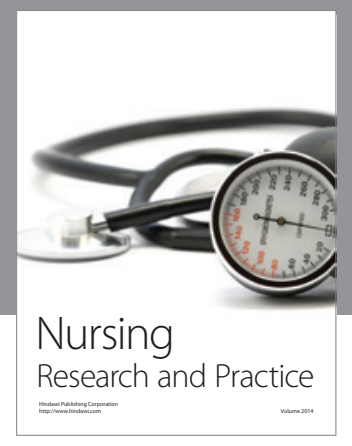

Nursing

Research and Practice

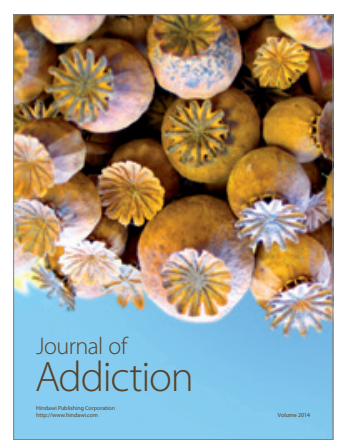

Child Development

Research

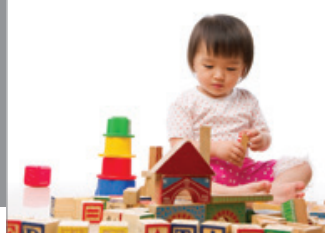

迥
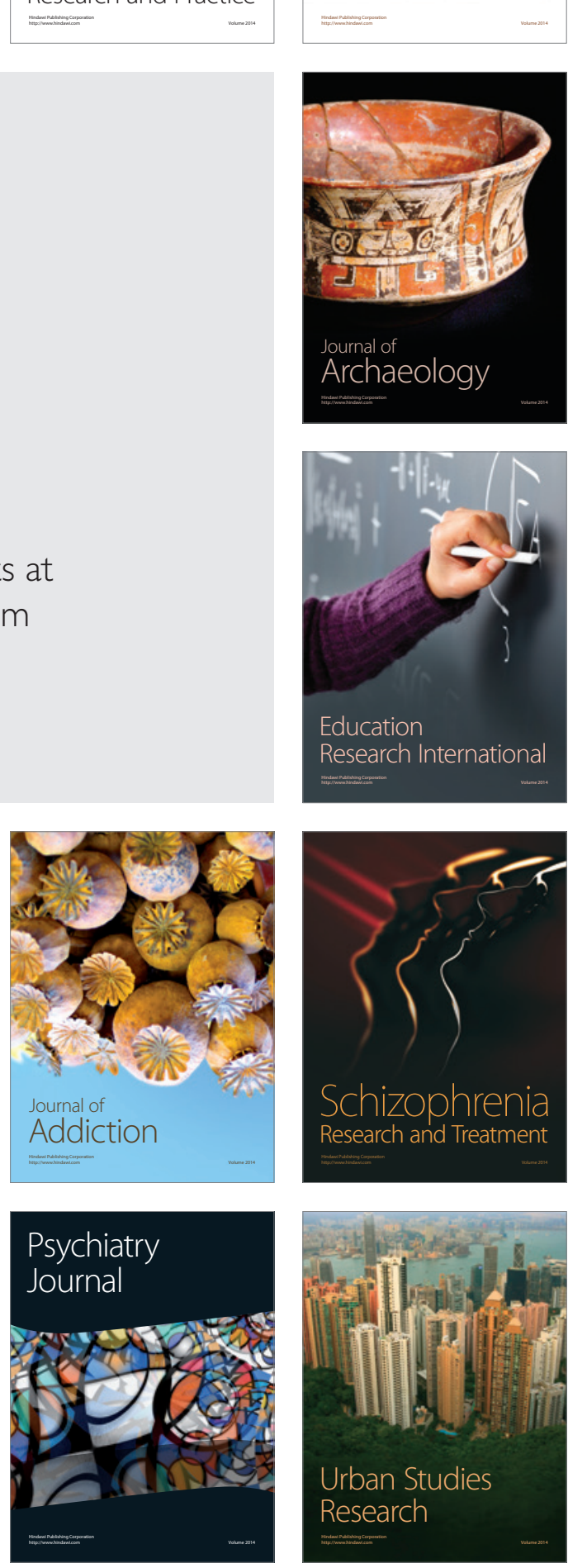